\title{
The Relationship Between Cardiovascular Disease and Inflammatory Arthritis, and the Potential Role of Exercise on the Burden of Illness: a Scoping Review
}

\author{
John Petrella*, Dalton Wolfe, Robert Petrella \\ University of Western Ontario \\ *Corresponding Author: jpetrel@uwo.ca
}

Copyright (C) 2013 Horizon Research Publishing All rights reserved.

\begin{abstract}
Inflammatory arthritis has been identified as a source of increased risk of cardiovascular disease (CVD) and patients with inflammatory arthritis face higher mortality compared to the general population. Hence, patients with inflammatory arthritis may require management of CVD that is different from the general population. Exercise has been described as a primary strategy for CVD risk management in the general population. However, it is unclear whether the presence of inflammatory arthritis and CVD risk factors requires different approaches to CVD risk management and in which aspects risk is changed (clinical or physiological). We conducted a scoping reviewof the literature to determine the association between inflammatory arthritis and CVD risk factors including prevention and treatment; specifically exercise treatment. Medical literature extracted using the databases SPORTDiscus, SCOPUS, and PUBMED, to determine the effect of exercise on the relationship between inflammatory arthritis and CVD was sought. We found 64 articles with relevant abstracts of studies and followed that by independent review by 2 reviewers. The majority of studies were excluded if the abstracts addressed an irrelevant study population, addressed only one of cardiovascular disease or inflammatory arthritis in isolation, did not provide a study design, or were lacking a complete abstract.
\end{abstract}

Keywords Inflammatory Arthritis, Exercise, Lifestyle Intervention

\section{Introduction}

The expected life span of patients with inflammatory arthritis is known to be shorter than in healthy controls. Further, the mortality difference between the general population and persons with inflammatory arthritis has been widening recently. ${ }^{1} \quad$ About $40 \%$ of deaths in patients with inflammatory arthritis are caused by cardiovascular causes, such as stroke. ${ }^{1} \quad$ Importantly, the literature also indicates that Cardiovascular diseases (CVD) are the leading cause of death in patients with inflammatory arthritis, as it is in the general population at large but to a much greater degree. ${ }^{2}$ Epidemiological studies confirm that those with inflammatory arthritis are 30-60\% more likely to suffer a CV event than subjects from the general population. ${ }^{3}$ The populations described in epidemiological studies have been mainly North American and observational in nature, with the number of subjects varying from 100 to upwards of 170000 subjects.

The literature has indicated that the use of biomarkers of arterial structure ( i.e. vessel wall thickness, thickness of plaques, and coronary artery calcification) $)^{4}$ and vascular function (measured using pulse wave analysis or flow mediated dilation)are potentially helpful endpoints in the examination of accelerated atherosclerosis and vascular disease that may suggest underlying biological processes which could be targeted, or are responsible for an apparently accelerated CVD morbidity in patients with inflammatory arthritis. ${ }^{5}$ These studies ${ }^{4,5,6}$ were mainly observational, cross sectional, allowing correlation associations to be made, but few provide definitive cause effect relationships. Hence, the evidence regarding the underlying relationship between inflammatory arthritis and CVD is still unclear as is the impact of preventive and maintenance treatment. CVD in the general population is attributed in large part to the lack of physical activity and sedentary behaviour. Exercise interventions have been shown to improve blood rheology and endothelial function, lower low grade inflammation and oxidative stress, reduce coronary atherosclerosis and facilitates vascular remodelling, angiogenesis and arteriogenesis. ${ }^{7}$ Life-long exercise is advised to the general population to reduce CVD risk in general population; patients with CVD are advised to exercise 3-5 days a week. ${ }^{7}$ Exercise also correlates with lower rates of mortality from CVD in the general population, with as many as 250000 deaths per year in the United States being attributable to a lack of regular physical activity. ${ }^{8}$ Unlike in the general population, an association 
between exercise effects on the relationship between CVD and inflammatory arthritis is unknown.

Inflammatory arthritis is positively correlated with an increased risk of cardiovascular disease (CVD) ${ }^{6}$ Recently interest has included understanding both the epidemiology and the biology of CVD in inflammatory arthritis diseases. In this paper, the risks of fatal and nonfatal CVD in adult patients with inflammatory arthritic diseases as well as underlying biological mechanisms are examined with respect to the risks experienced by the general population. The contribution of traditional and disease-related cardiovascular risk factors to the observed excess CVD risk is noted as is the effect of treatment. In particular, the effect of exercise training on the relationship between CVD and inflammatory arthritis will be elucidated to detect current gaps in knowledge and potential areas for potential research.

\section{Search Criteria}

The databases SPORTDiscus, SCOPUS, and PUBMED were searched to determine effect of exercise on the relationship between cardio vascular disease and inflammatory arthritis. Searches were limited to studies published between 2000-January 2012, and published as full reports in the English language. Hand searching of references from relevant articles was also conducted to identify potential articles which were not found through the databases searched. The following search strategy terms were used; cardio vascular disease and inflammatory arthritis; cardio vascular disease and inflammatory arthritis and exercise; cardio vascular disease and inflammatory arthritis and exercise training.

\section{Inclusion/Exclusion Criteria}

The study populations included were men and/or women, aged 18 years or older. Reviews were included in order to identify further relevant articles. Articles which addressed treatment, the effect of drugs, risk factors, complications, and comorbidity of cardio vascular disease and inflammatory arthritis and included exercise as an intervention, treatment, or outcome were included.

\section{Results}

In the initial search of the databases, a total of 544 articles were identified. Articles were then excluded on review of extracted abstracts if they addressed an irrelevant study population, addressed only one of cardiovascular disease or inflammatory arthritis in isolation, did not provide a study design, or were lacking an abstract. Sixty four articles following independent verification by two reviewers of the abstracts were deemed relevant to the search for studies that addressed the relationship between exercise, cardio vascular disease and inflammatory arthritis. Of these 64 articles with relevant abstracts, 20 were reviews and were not included. Of the remaining 44 articles, 12 were judged to be most relevant to the scoping review and made up the basis of the results sections; CVD function and inflammatory arthritis, CVD, inflammatory arthritis and exercise of this paper. 32 were included as background information and used in the Introduction and Epidemiology sections as well as in the Risk factors for CVD and inflammatory arthritis section. Papers were excluded from this review because; the paper didn't address the keyword search criteria, they were not retrievable beyond the abstract, we couldn't obtain a full manuscript, or the papers were previously published data that was already considered in the most relevant papers.

Of the 12 selected studies which are included in the PICO table below, 3 studies described CVD and related risk factors epidemiology. These studies found that patients with inflammatory arthritis have increased risk of $\mathrm{CVD}^{6}$ Specifically a higher risk of myocardial infarction was associated with inflammatory arthritis, ${ }^{9}$ and inflammatory arthritis may be associated with micro vascular dysfunction. ${ }^{10}$ Of patients with inflammatory arthritis, it was shown that atherosclerosis events was more likely to occur in older men, relative to women or younger men. ${ }^{11}$

Three studies described the relationship between rheumatoid arthritis and arterial stiffness. Specifically, these studies suggest that cardiac valvular calcification is more prevalent in patients with inflammatory arthritis than healthy controls. ${ }^{12}$ This valvular calcification prevalence suggests increased arterial stiffness is associated with inflammatory arthritis, as shown by and increased augmentation index (AIX) and pulse wave velocity (PWV), in patients with inflammatory arthritis. ${ }^{13}$ The increased arterial stiffness associated with inflammatory arthritis was not however, associated with constitutional symptoms, such as muscle aches, lack of appetite etc. ${ }^{5}$

Two studies described the effect of treatment on the relationship between inflammatory arthritis and cardiovascular disease. Patients, 6,578, with inflammatory arthritis taking methotrexate (MTX) had had lower incidence rates of ischemic heart disease than patients taking non biological anti-psoriatic drugs other than MTX. ${ }^{14}$ In a study about therapy and its effects on arterial stiffness, it was found that of the 64 patients with inflammatory arthritis, in which 22 received tocilizumab (TCZ), 21 received ethanercept (ETN) and 21 received adalimumab (ADA), all three types of therapy limited arterial stiffness to a similar extent. ${ }^{15}$

One study described inflammation effects on CVD. In a study of 183 subjects, 59 with inflammatory arthritis, and 123 healthy controls, findings argued against a causal role of C-reactive protein in atherosclerosis. ${ }^{4}$

Three studies had to do with biomarkers. The cardiac biomarker NT-proBNP was able to identify CVD risk in patients taking nonsteroidal anti-inflammatory drugs (NSAID), in a study of 6273 patients with inflammatory arthritis. ${ }^{16}$ Further, there was no significant association between vascular endothelial growth factor and increased 
risk of CVD in a study of 661 patients with inflammatory arthritis. ${ }^{17}$

No studies addressed the relationship between CVD, inflammatory arthritis and exercise (exercise training, fitness level, or relationship between fitness level and severity of disease).

\section{Discussion}

\subsection{Epidemiology of CVD and Inflammatory Arthritis}

Traditional CVD risk factors (TRF) including aging, male gender, smoking, hypertension, diabetes, and hypercholesterolemia were confirmed to be greater in inflammatory arthritis. We also found aggressive treatment of disease, and screening for and managing TRFs are important to reduce the burden of illness of inflammatory arthritis. No studies observed the impact of exercise training interventions on CVD risk factors in patients with inflammatory arthritis. However some studies did comment on exercise related cardiovascular variables such as endothelial function. Some correlations between classic risk factors and CVD risk in people with inflammatory arthritis seem paradoxical but may be understood due to biological alterations. More research is needed to further broaden our knowledge regarding the relationship between CVD, inflammatory arthritis, and exercise treatment as a modifying strategy for increased burden of CVD in this population.

The relationship which exists between inflammatory arthritis and CVD has been well described and established in many studies. It appears to be clear that those suffering from inflammatory arthritis have a greater risk of CVD than those in the general population, and that those with inflammatory arthritis have increased mortality rates compared to the general population. ${ }^{2}$ While the impact of exercise on this relationship between the two conditions could potentially have benefit, it is unclear whether there is data to support this assumption. Certainly the implications of exercise as a treatment or in the prevention of severity of the relationship of either condition (particularly concomitant CVD and inflammatory arthritis) could be important for patients and clinicians.

This review has provided the current state of knowledge regarding the relationship between $\mathrm{CVD}$, inflammatory arthritis and exercise, which shows a clear gap in knowledge regarding the interaction of exercise as a treatment for concomitant CVD and inflammatory arthritis.

Patients with inflammatory arthritis have been found to have increased mortality compared to the general population. ${ }^{2}$ This increased mortality is largely attributed to CVD's, such as stroke and ischemic heart disease, as $40 \%$ of all deaths of individuals with inflammatory arthritis. ${ }^{3}$ The increased risk of CVD in patients with inflammatory arthritis suggests a relationship between the two conditions. Of the mortality studies conducted, most addressed population of North American or European origin.
Despite the knowledge of the relationship between the two conditions, it remains unclear how quickly after symptoms of inflammatory arthritis become apparent, that the excess of CVD mortality risk becomes evident. For example, in a Dutch inception cohort of 1,049 patients with RA, increased mortality became clear at around 10 years after RA diagnosis. ${ }^{3}$ The gap between the risk of CVD among those in the general population compared to the risk of CVD amongst those with inflammatory arthritis appears to be increasing. ${ }^{1}$

Several studies have shown that patients with inflammatory arthritis are at a higher risk of IHD. ${ }^{18,19}$ Data from the Rochester Epidemiology Project show that there was an increased risk of unrecognized MI after the diagnosis of RA. ${ }^{9}$ In two large Swedish cohorts suggest accelerated atherosclerosis begins around the time of, or before, the onset of symptoms of inflammatory arthritis, and not at the time of diagnosis.

Existing literature suggests that after MI, patients with inflammatory arthritis have increased rates of heart failure and death. ${ }^{20,21}$ Conversely, another study found patients with MI, those with inflammatory arthritis had greater likelihood of undergoing thrombolysis and percutaneous coronary intervention $(\mathrm{PCI})$, but were not as likely to receive medical therapy and/or coronary artery bypass grafting, than the general population. ${ }^{22}$

Accelerated atherosclerosis was also at increased prevalence amongst patients with inflammatory arthritis compared to the general population. ${ }^{23,24,25,26,27}$ There were increased chances of atherosclerotic plaques forming in the inflammatory arthritic population, which also leads to increased amount of myocardial infarction occurring in this population, ranging from a 2 -fold to a greater than 10 fold increased risk of MI when compared to the general population. ${ }^{23,27}$ There was a raised relative risk of MI especially noticeable in young adults with inflammatory arthritis. ${ }^{24}$ In the women inflammatory arthritis population, MI risk was $>50$ times more likely compared to those in the general population. ${ }^{24}$

Patients with inflammatory arthritis have increased risk of incurring heart failure, with regards to the general population. ${ }^{28,11}$ Inflammatory arthritis patients were at decreased chance of having typical signs and symptoms of heart failure. ${ }^{29}$ Those with inflammatory arthritis and heart failure have worse outcomes compared to those patients without inflammatory arthritis, as they have about twice the risk of death in the period directly after experiencing heart failure. ${ }^{23}$ Mechanisms involved with heart failure appear to differ in those with inflammatory arthritis versus the control population as well. ${ }^{29}$

\subsection{Effect of Treatment on CVD and Inflammatory Arthritis Health Outcomes}

Many medications aimed at reducing inflammatory arthritic symptoms may worsen traditional CVD risk factors. NSAIDs, cortico steroids, leflunomide and ciclosporin are correlated with greater risk of hypertension, a traditional 
CVD risk factor. ${ }^{30}$ These treatments are associated with an increased risk of CVD events in patients with inflammatory arthritis. ${ }^{30}$ The issue of NSAID associated CVD risk has not however been examined in an exclusively inflammatory arthritis population.

The use of biological agents such as methotrexate and anti-TNF agents have been found to reduce CVD risk. ${ }^{31,32,33,34}$ This decreased CVD risk is largely attributable to the evidence that these biological agents control long term systemic inflammation.

While primary prevention of cardiovascular events in the general population has shown statins to be preventative, it remains unclear whether statins would have additional anti-inflammatory effects useful for patients with inflammatory arthritis. ${ }^{35}$ Statins have not been used sufficiently in the inflammatory arthritis population, and the effect of the use statins as a treatment method, remain far from definitive.

Many studies link markers of inflammatory arthritis to increased risk of CVD events and deaths, after adjustment for traditional CVD risk factors. ${ }^{36,37,38}$ In a study of 231 male veterans with inflammatory arthritis, there was increased prediction of CVD events occurring. ${ }^{39}$

\subsection{Risk Factors for CVD and Inflammatory Arthritis}

In the population at large, studies have elucidated risk factors associated with CVD onset. These risk factors include, smoking, increased age, male gender, hypertension, hypercholesterolemia, and diabetes. These risk factors are termed, traditional CVD risk factors.

The increased prevalence of CVD in patients with inflammatory arthritis could be attributable to the fact that traditional CVD risk factors (TRFs) are seen more often in those with inflammatory arthritis.

Hypertension in patients with inflammatory arthritis is a common occurrence. Recent meta-analysis of 7 case control studies (1,053 patients with RA) found the prevalence of hypertension to be the same in patients with inflammatory arthritis as in controls. ${ }^{40}$ Despite these findings however, evidence leads to hypertension being underdiagnosed and undertreated in patients with inflammatory arthritis, compared to the general population. ${ }^{41}$

Smoking has been shown to be a risk factor for the development of inflammatory arthritis. Smokers with inflammatory arthritis show increased chances of cardiovascular events, however the relative risk was not to the same high degree as what is seen in the general population. ${ }^{41}$

The incidence of diabetes was increased in people with inflammatory arthritis when compared to controls in a recent meta-analysis $\left(1,239\right.$ patients with inflammatory arthritis) ${ }^{40}$ In spite of this increased prevalence, the use of hydroxchloroquine has shown to decrease risk of diabetes in those with inflammatory arthritis by about $77 \%{ }^{42}$

Insulin resistance has been found to be at a greater frequency in those with inflammatory arthritis than those in the general population. ${ }^{43}$

Low physical activity has a direct relationship to obesity and insulin resistance, symptomatic among patients with inflammatory arthritis. This could be largely attributed to symptoms associated with inflammatory arthritis, including pain, stiffness, poor mobility, and the advice they may receive stressing the importance of rest. Using the Paffenbarger Physical Exercise Index, Mancuso et al, found patients with inflammatory arthritis expended fewer kcals per week exercising than controls. This dichotomy was mainly attributed to less exercise by the patients with inflammatory arthritis. ${ }^{44}$

In the study Holmes et al 2008, it was found that C-reactive protein (CRP) was associated with improved endothelial function, which was contrary to belief previous to this study's findings. This lack of correlation between CRP and CVD would be expected in inflammatory arthritis if CRP arising from a stimulus unrelated to atherosclerosis is unrelated to CVD. The authors suggest that the findings of this study and the use of CRP in inflammatory arthritis should be further evaluated before being used as a risk marker of CVD. ${ }^{4}$

Ruff et al 2010 found the biomarker NT-proBNP was found to be associated with increased risk of cardiovascular death, thrombotic events, and heart failure when levels of NT-proBNP was at increased levels. ${ }^{16}$

The biomarkers VEGFA rs2010963 and rs1570360 polymorphisms were not significantly associated with clinically evident $\mathrm{CV}$ disease found in patients with inflammatory arthritis. ${ }^{17}$

\subsection{CVD Function and Inflammatory Arthritis}

Cardio vascular function as indicated by premature or disease related arterial stiffness for example maybe an early signal of accelerated disease in inflammatory arthritis. While arterial stiffness is prevalent in patients with inflammatory arthritis, no individual constitutional symptoms were significantly associated with increased arterial stiffness. ${ }^{5}$ To reduce arterial stiffness, Kume et al, 2011, found that the effects of the treatments TCZ, ETN, and ADA had similar effect in the reduction of arterial stiffness. ${ }^{15}$

\subsection{CVD, Inflammatory Arthritis and Exercise}

Despite the well-established relationship in the general population between higher levels of cardiovascular fitness or the effect of exercise training on cardio vascular disease prevention and/or management and similarly with management of inflammatory arthritis, we could not find any studies that addressed the potential relationship between exercise and the concomitant presence of CVD and inflammatory arthritis. Specifically we could not find any studies or reviews that addressed levels of fitness or the effect of exercise training on the relationship between CVD and inflammatory arthritis. Certainly this suggests an important of future research and potentially clinical intervention. 
Table 1. PICO Tables for selected papers

\begin{tabular}{|c|c|c|c|c|}
\hline Study & Population & Intervention/Assessement & Comparison & Outcomes \\
\hline $\begin{array}{l}\text { Chen et al. } 2011 \\
\text { (Retrospective cohort study) }\end{array}$ & $\begin{array}{l}179200 \text {, patients with diagnosis of } \\
\text { psoriasis or psoriasis arthritis, in } \\
\text { nationwide cohort study }\end{array}$ & Patients taking methotrexate (MTX). 6,578 subjects & $\begin{array}{c}\text { Patients taking non } \\
\text { biological anti-psoriatic } \\
\text { drugs other than MTX. 5, } \\
471 \text { subjects } \\
\end{array}$ & $\begin{array}{c}\text { Incidence rates of ischemic heart diseases } \\
\text { were } 666 \text { and } 830 \text { cases per } 1000 \\
\text { person-years, in MTX cohort and reference } \\
\text { cohort respectively } \\
\end{array}$ \\
\hline $\begin{array}{l}\text { Costa et al. } 2011 \\
\text { (Case control study) }\end{array}$ & 40 subjects & $\begin{array}{l}20 \text { patients with PsA. The assessment was of aortic } \\
\text { stiffness in patients with PsA compared to healthy } \\
\text { controls }\end{array}$ & 20 healthy control subjects & $\begin{array}{c}\text { Study shows PsA patients have increase of } \\
\text { aortic stiffness, supporting hypothesis that } \\
\text { PsA is associated with increased } \\
\text { cardiovascular risk } \\
\end{array}$ \\
\hline $\begin{array}{l}\text { Crilly et al. } 2010 \\
\text { (Observational study) }\end{array}$ & $\begin{array}{l}103 \text { ambulatory RA patients without } \\
\text { overt arterial disease }\end{array}$ & $\begin{array}{l}\text { The assessment in this study was of RA patients, and } \\
\text { if constitutional symptoms increased arterial stiffness }\end{array}$ & & $\begin{array}{c}\text { No individual constitutional symptoms } \\
\text { were significantly associated with } \\
\text { increased arterial stiffness }\end{array}$ \\
\hline $\begin{array}{l}\text { Holmes et al. } 2010 \\
\text { (Case control study) }\end{array}$ & 183 subjects & 59 patients with rheumatoid arthritis (RA). & 123 healthy control subjects & $\begin{array}{l}\text { Findings argue against causal role of } \\
\text { C-reactive protein in atherosclerosis }\end{array}$ \\
\hline $\begin{array}{l}\text { Holmqvist et al. } 2010 \\
\text { (Nationwide cohort study) }\end{array}$ & 44493 subjects in cohort study & 7469 subjects with rheumatoid arthritis & $\begin{array}{l}37024 \text { subjects from } \\
\text { general population }\end{array}$ & $\begin{array}{l}\text { The risk of myocardial infarction is } \\
\text { associated with RA }\end{array}$ \\
\hline $\begin{array}{l}\text { Kume et al. } 2011 \\
\text { (Randomized control trial) }\end{array}$ & $\begin{array}{l}64 \text { patients with rheumatoid arthritis } \\
\text { (RA) }\end{array}$ & $\begin{array}{c}22 \text { subjects received tocilizumab (TCZ), } 21 \text { received } \\
\text { ethanercept (ETN), and } 21 \text { received adalimumab } \\
\text { (ADA). The assessment in this study had } 3 \text { treatment } \\
\text { arms with no placebo/control }\end{array}$ & $\mathrm{n} / \mathrm{a}$ & $\begin{array}{l}\text { All three types of therapy limited arterial } \\
\text { stiffness to a similar extent }\end{array}$ \\
\hline $\begin{array}{c}\text { Provan et al. } 2011 \\
\text { (Longitudinal observational } \\
\text { study) }\end{array}$ & $\begin{array}{c}238 \text { patients with early rheumatoid } \\
\text { arthritis (RA) }\end{array}$ & 108 patients available for 15 year follow up. & $\mathrm{n} / \mathrm{a}$ & $\begin{array}{c}\text { Inflammation early in RA was associated } \\
\text { with increased augmentation index (AIX) } \\
\text { and pulse wave velocity (PWV), } 2 \\
\text { measures of arterial stiffness } \\
\end{array}$ \\
\hline $\begin{array}{l}\text { Rodriguez et al. } 2011 \\
\text { (Observational study) }\end{array}$ & $\begin{array}{l}661 \text { patients with rheumatoid arthritis } \\
\text { (RA) }\end{array}$ & $\begin{array}{l}\text { The assessment in this study was an observational } \\
\text { study }\end{array}$ & $\mathrm{n} / \mathrm{a}$ & $\begin{array}{c}\text { No significant association between } \\
\text { vascular endothelial growth factor and } \\
\text { increased risk of cardiovascular disease in } \\
\text { RA patients }\end{array}$ \\
\hline $\begin{array}{l}\text { Ruff et al. } 2011 \\
\text { (Prospective, nested } \\
\text { biomarker study) }\end{array}$ & $\begin{array}{l}6273 \text { patients with rheumatoid or } \\
\text { osteoarthritis }\end{array}$ & $\begin{array}{l}\text { Patients took chronic nonsteroidal anti-inflammatory } \\
\text { drugs (NSAID) }\end{array}$ & $\begin{array}{l}\mathrm{n} / \mathrm{a}^{*} \text { no comparison group } \\
\text { present }\end{array}$ & $\begin{array}{c}\text { The cardiac biomarker NT-proBNP is able } \\
\text { to identify cardiovascular risk in patients } \\
\text { taking NSAID treatment }\end{array}$ \\
\hline $\begin{array}{l}\text { Urowitz et al. } 2010 \\
\text { (Multinational inception } \\
\text { cohort study) }\end{array}$ & $\begin{array}{l}1249 \text { patients in cohort with systemic } \\
\text { lupus erythematosus (SLE) }\end{array}$ & $\begin{array}{c}\text { The assessment in this study was an observational } \\
\text { study }\end{array}$ & $\mathrm{n} / \mathrm{a}$ & $\begin{array}{l}\text { SLE cohort followed for } 8 \text { years, } 97 \\
\text { vascular events of which } 31 \text { were attributed } \\
\text { to atherosclerosis. Atherosclerosis events } \\
\text { were more likely to occur in older men. }\end{array}$ \\
\hline $\begin{array}{l}\text { Yalcin et al. } 2011 \\
\text { (Observational study) }\end{array}$ & $\begin{array}{l}28 \text { patients with Ankylosingspondilitis } \\
\text { (AS) }\end{array}$ & $\begin{array}{c}\text { All patients underwent Tc-MIBI gated myocardial } \\
\text { perfusion SPECT }\end{array}$ & $\mathrm{n} / \mathrm{a}$ & $\begin{array}{l}\text { AS may be associated with micro vascular } \\
\text { dysfunction and gated myocardial } \\
\text { perfusion could be valuable for AS patients } \\
\text { regarding heart function }\end{array}$ \\
\hline $\begin{array}{c}\text { Yiu et al. } 2011 \\
\text { (Case control study) }\end{array}$ & 170 subjects & $\begin{array}{l}110 \text { patients with rheumatoid arthritis (RA) and } \\
\text { systemic lupus erythematosus (SLE) }\end{array}$ & $\begin{array}{l}60 \text { age and sex matched } \\
\text { healthy controls }\end{array}$ & $\begin{array}{l}\text { Cardiac valvular calcification is more } \\
\text { prevalent in RA and SLE patients, than in } \\
\text { healthy controls }\end{array}$ \\
\hline
\end{tabular}




\section{Conclusion}

Inflammatory arthritis in adults presents an increased risk of cardiovascular events and disease, in comparison to adults in the general population. As disease duration increases, the risk of CVD events increases as well. Further, patients with inflammatory arthritis who experience CVD events such as MI or CHF have worse health outcomes than adults in the general population. The effect of exercise, as a treatment for cardiovascular disease or inflammatory arthritis is well established. However, the effect of exercise in patients with CVD and inflammatory arthritis in this scoping review revealed an absence of research evidence supporting any recommendations for a therapeutic role.

Clinicians dealing with CVD and inflammatory arthritis need further research to further our understanding of the relationship between these two conditions and specific role for exercise training. For example, future research should focus on the interactions between both TRFs and disease related risk factors, and the effects of exercise on the relationship between CVD and inflammatory arthritis.

\section{REFERENCES}

[1] Gonzalez, A. et al. Mortality trends in rheumatoid arthritis: the role of rheumatoid factor. J. Rheumatol. 35, 1009-1014 (2008).

[2] Sokka, T., Abelson, B. \& Pincus, T. Mortality in rheumatoid arthritis: 2008 update. Clin. Exp. Rheumatol. 26 (Suppl. 51), S35-S61 (2008).

[3] Avina-Zubieta, J. A. et al. Risk of cardiovascular mortality in patients with rheumatoid arthritis: a meta-analysis of observational studies. Arthritis Rheum. 59, 1690-1697 (2008).

[4] Holmes, M.V. et al. Paradoxical Association of C-Reactive Protein with Endothelial Function in Rheumatoid Arthritis. PLoS ONE 5(4): e10242 (2010).

[5] Crilly, M. A. et al. Constitutional symptoms at the onset of rheumatoid arthritis and subsequent arterial stiffness. Clinical Rheumatology. 29, 1113-1119 (2010).

[6] Costa, L. et al. Psoriatic arthritis is associated with increased arterial stiffness in the absence of known cardiovascular risk factors: a case control study. Clinical Rheumatology. 10, 1007-1892 (2011).

[7] Ahlehoff, et al. Psoriasis is associated with clinically significant cardiovascular risk: a Danish nationwide cohort study. Journal of Internal Medicine. Aug: 270(2): 147-57 (2011).

[8] Pate, G. et al. Anti-inflammatory effects of statins in patients with aortic stenosis. Journal of Cardiovascular Pharmacology Therapy. Sep;8(3);201-6, (2003).

[9] Holmqvist, M.E. et al. Rapid increase inmyocardial infarction risk following diagnosis of rheumatoid arthritis amongst patients diagnosed between 1995 and 2006 .
Journal of Internal Medicine. 268, 578-585 (2010).

[10] Yalcin, H. et al. Left ventricular wall function abnormalities in patients with ankylosing spondylitis evaluated by gated myocardial perfusion scintigraphy. Rev Esp Med Nucl. 30:5, 292-296 (2011).

[11] Urowitz, M. B. et al. Atherosclerotic Vascular Events in a Multinational Inception Cohort of Systemic Lupus Erythematosus. Arthritis and Care Research. 62:6, 881-887 (2010).

[12] Yiu, K-H. et al. Relationship Between Cardiac Valvular and Arterial Calcification in Patients with Rheumatoid Arthritis and Systemic Lupus Erythematosus. Journal of Rheumatology. 38:4 (2011).

[13] Provan, S. A. et al. Early Prediction of Increased Arterial Stiffness in Patients with Chronic Inflammation: A 15-year Follow up Study of 108 Patients with Rheumatoid Arthritis. Journal of Rheumatology. 38:4 (2011).

[14] Chen, Y.J. et al. Cardiovascular risk and methotrexate use in psoriasis and psoriatic arthritis. Arthritis Rheum. 10, 1002 (2011).

[15] Kume, K. et al. Tocilizumab Monotherapy Reduces Arterial Stiffness as Effectively as Etanercept or Adalimumab Monotherapy in Rheumatoid Arthritis: An Open-label Randomized Controlled Trial. Journal of Rheumatology. 38: 10 (2011).

[16] Ruff, C. T. et al. Evaluation of NT-proBNP and High Sensitivity C-Reactive Protein for Predicting Cardiovascular Risk in Patients with Arthritis Taking Longterm Nonsteroidal Antiinflammatory Drugs. Journal of Rheumatology. 38:6 (2011).

[17] Rodriguez- Rodriguez, L. et al. Vascular endothelial growth factor A and cardiovascular disease in rheumatoid arthritis patients. Tissue Antigens. 77. 291-297 (2011).

[18] Watson, D. J., Rhodes, T. \& Guess, H. A. All-cause mortality and vascular events among patients with rheumatoid arthritis, osteoarthritis, or no arthritis in the UK General Practice Research Database. J. Rheumatol. 30, 1196-1202 (2003).

[19] Maradit-Kremers, H. et al. Increased unrecognized coronary heart disease and sudden deaths in rheumatoid arthritis: A population-based cohort study. Arthritis Rheum. 52, 402-411 (2005).

[20] Sodergren, A. et al. Increased incidence of and impaired prognosis after acute myocardial infarction among patients with seropositive rheumatoid arthritis. Ann. Rheum. Dis. 66, 263-266 (2007).

[21] Douglas, K. M. et al. Excess recurrent cardiac events in rheumatoid arthritis patients with acute coronary syndrome. Ann. Rheum. Dis. 65, 348-353 (2006).

[22] Maradit Kremers, $H$. et al. High ten-year risk of cardiovascular disease in newly diagnosed rheumatoid arthritis patients: a population-based cohort study. Arthritis Rheum. 58, 2268-2274 (2008).

[23] Davis, J. M. III et al. Mortality following heart failure is higher among rheumatoid arthritis subjects compared to non-RA subjects [abstract 883]. Arthritis Rheum. 54 (Suppl.), S387 (2006). 
[24] Esdaile, J. M. et al. Traditional Framingham risk factors fail to fully account for accelerated atherosclerosis in systemic lupus erythematosus. Arthritis Rheum. 44, 2331-2337 (2001).

[25] Roman, M. J. et al. Prevalence and correlates of accelerated atherosclerosis in systemic lupus erythematosus. N. Engl. J. Med. 349, 2399-2406 (2003).

[26] Fischer, L. M., Schlienger, R. G., Matter, C., Jick, H. \& Meier, C. R. Effect of rheumatoid arthritis or systemic lupus erythematosus on the risk of first-time acute myocardial infarction. Am. J. Cardiol. 93, 198-200 (2004).

[27] Van Doornum, S. et al. Rheumatoid arthritis patients receive less frequent acute reperfusion and secondary prevention therapy after myocardial infarction compared with the general population. Arthritis Res. Ther. 12, R183 (2010).

[28] Haque, S. \& Bruce, I. N. Cardiovascular outcomes in systemic lupus erythematosus: big studies for big questions. J. Rheumatol. 36, 467-469 (2009).

[29] Davis, J. M. III et al. The presentation and outcome of heart failure in patients with rheumatoid arthritis differs from that in the general population. Arthritis Rheum. 58, 2603-2611 (2008).

[30] Solomon, D. H. et al. Immunosuppressive medications and hospitalization for cardiovascular events in patients with rheumatoid arthritis. Arthritis Rheum. 54, 3790-3798 (2006).

[31] Naranjo, A. et al. Cardiovascular disease in patients with rheumatoid arthritis: results from the QUEST-RA study. Arthritis Res. Ther. 10, R30 (2008).

[32] Listing, J. et al. Does tumor necrosis factor alpha inhibition promote or prevent heart failure in patients with rheumatoid arthritis? Arthritis Rheum. 58, 667-677 (2008).

[33] Salliot, C. \& van der Heijde, D. Long-term safety of methotrexate monotherapy in patients with rheumatoid arthritis: a systematic literature research. Ann. Rheum. Dis. 68, 1100-1104 (2009).
[34] Westlake, S. L. et al. The effect of methotrexate on cardiovascular disease in patients with rheumatoid arthritis: a systematic literature review. Rheumatology (Oxford) 49, 295-307 (2010).

[35] McCarey, D. W. et al. Trial of Atorvastatin in Rheumatoid Arthritis (TARA): double-blind, randomised placebo-controlled trial. Lancet 363, 2015-2021 (2004).

[36] Farragher, T. M., Lunt, M., Bunn, D. K., Silman, A. J. \& Symmons, D. P. Early functional disability predicts both all-cause and cardiovascular mortality in people with inflammatory polyarthritis: results from the Norfolk Arthritis Register. Ann. Rheum. Dis. 66, 486-492 (2007).

[37] Maradit-Kremers, H. et al. Raised erythrocyte sedimentation rate signals heart failure in patients with rheumatoid arthritis. Ann. Rheum. Dis. 66, 76-80 (2007).

[38] Liang, K. P. et al. Autoantibodies and the risk of cardiovascular events. J. Rheumatol. 36, 2462-2469 (2009).

[39] Banerjee, S. et al. Cardiovascular outcomes in male veterans with rheumatoid arthritis. Am. J. Cardiol. 101, 1201-1205 (2008).

[40] Boyer, J. F., Gourraud, P. A., Cantagrel, A., Davignon, J. L. \& Constantin, A. Traditional cardiovascular risk factors in rheumatoid arthritis: A meta-analysis. Joint Bone Spine 78, 179-183 (2011)

[41] Panoulas, V. F. et al. Prevalence and associations of hypertension and its control in patients with rheumatoid arthritis. Rheumatology (Oxford) 46, 1477-1482 (2007).

[42] Wasko, M. C. Rheumatoid arthritis and cardiovascular disease. Curr. Rheumatol. Rep. 10, 390-397 (2008).

[43] Dessein, P. H. \& Joffe, B. I. Insulin resistance and impaired beta cell function in rheumatoid arthritis. Arthritis Rheum. 54, 2765-2775 (2006).

[44] Mancuso, C. et al. Comparison of energy expenditure from lifestyle physical activities between patients with rheumatoid arthritis and healthy controls. Arthritis Rheum. 57, 672-678 (2007). 